\title{
Acúmulo de nutrientes pela alface destinada à produção de sementes
}

\author{
Cristiaini Kano $^{1}$; Antonio Ismael Inácio Cardoso² ; Roberto L Villas Bôas $^{3}$
}

${ }^{1}$ APTA/Pólo Leste Paulista, C. Postal 01, 13910-000 Monte Alegre do Sul-SP; ${ }^{2}$ UNESP-FCA, Depto. Produção Vegetal, Setor Horticultura, C. Postal 237, 18610-307 Botucatu-SP; ${ }^{3}$ UNESP-FCA, Depto. Recursos Naturais, Setor Ciência do Solo; criskano@hotmail.com; ismaeldh@fca.unesp.br; rlvboas@fca.unesp.br

\section{RESUMO}

O objetivo deste trabalho foi determinar a curva de acúmulo de nutrientes pela planta de alface destinada à produção de sementes. O experimento foi conduzido na Fazenda Experimental São Manuel, pertencente à Faculdade de Ciências Agronômicas da Universidade Estadual Paulista, no período de 25/09/03 a 19/02/04. O delineamento experimental utilizado foi em blocos ao acaso com cinco repetições e seis tratamentos (épocas de coleta das plantas: 0, 20, 34, 49, 69 e 112 dias após o transplante (DAT)). Foi utilizada a alface crespa cultivar Verônica, sendo avaliados o acúmulo da massa seca e de N, P, K, $\mathrm{Ca}, \mathrm{Mg}, \mathrm{S}, \mathrm{B}, \mathrm{Cu}, \mathrm{Fe}, \mathrm{Mn}$ e $\mathrm{Zn}$ na parte aérea das plantas. O maior incremento da massa seca das plantas ocorreu após o ponto comercial (34 DAT). O período de maior demanda de macronutrientes foi entre o início do pendoamento e o início do florescimento. Observa-se que para a maioria dos micronutrientes o período de maior exigência foi após o início do florescimento. A ordem decrescente de acúmulo de nutrientes foi: $\mathrm{K}>\mathrm{N}>\mathrm{Ca}>\mathrm{Mg}>\mathrm{P}>\mathrm{S}>\mathrm{Fe}>\mathrm{Mn}>\mathrm{Zn}>\mathrm{B}>\mathrm{Cu}$.

Palavras-chave: Lactuca sativa, nutriente, demanda nutricional.

\begin{abstract}
\section{Nutrients uptake by lettuce plants for seed production}

The nutrients uptake curve of lettuce plants for seed production was evaluated. The experiment was carried out from September 2003 to February 2004 at the Faculdade de Ciências Agronômicas of the Universidade Estadual Paulista, in Botucatu, São Paulo State, Brazil. A randomized block design was used, with five replicates and six treatments (periods of plant collection: 0, 20, 34, 49, 69 and 112 days after transplant (DAT)). We utilized the Verônica lettuce cultivar and evaluated the dry mass and the $\mathrm{N}, \mathrm{P}, \mathrm{K}, \mathrm{Ca}, \mathrm{Mg}, \mathrm{S}, \mathrm{B}$, $\mathrm{Cu}, \mathrm{Fe}, \mathrm{Mn}$ and $\mathrm{Zn}$ accumulated in the aboveground part of the plants. The greatest increase in the plant dry matter occurred after the marketable point (34 DAT). The period of greatest demand for nutrients was between the beginning of the stem elongation stage and the beginning of the flowering stage. We also observed that for most micronutrients the period of highest demand was after the beginning of the flowering stage. Nutrients accumulation in descending order was: $\mathrm{K}>\mathrm{N}>\mathrm{Ca}>\mathrm{Mg}>\mathrm{P}>\mathrm{S}>\mathrm{Fe}>\mathrm{Mn}>\mathrm{Zn}>\mathrm{B}>\mathrm{Cu}$.
\end{abstract}

Keywords: Lactuca sativa, nutrient, nutritional demand.

(Recebido para publicação em 30 de outubro de 2009; aceito em 18 de fevereiro de 2011) (Received on October 30, 2009; accepted on February 18, 2011)

$\mathrm{N}$ os últimos anos, o mercado está exigindo maior qualidade do produto e reduções nos custos de produção. Para isso, é necessário que as práticas culturais relacionadas aos tratamentos fitossanitários e às adubações sejam realizadas com eficiência, sem desperdício. O conhecimento da quantidade de nutrientes acumulada nas plantas é uma importante ferramenta para as recomendações econômicas de adubação (Vitti et al., 1994; Raij et al., 1996).

O uso de curvas de acúmulo de nutrientes para as diversas espécies de hortaliças mostra-se como uma boa indicação da necessidade de nutrientes em cada etapa de desenvolvimento da planta; contudo, essas informações são ainda bastante limitadas (Villas Bôas et al., 2001), principalmente quando se visa a produção de sementes da maioria das hortaliças.

Em média, as plantas possuem cerca de $5 \%$ de nutrientes minerais na massa seca total, porém existem grandes diferenças entre as espécies. As quantidades totais de nutrientes exigidas por uma cultura dependem, dentre outros fatores, da produtividade. Por outro lado, a absorção de nutrientes é diferente, de acordo com a fase de desenvolvimento da planta, intensificando-se com o florescimento e a frutificação (Haag \& Minami, 1981; Vitti et al., 1994; Raij et al., 1996).

As hortaliças diferenciam-se nas exigências nutricionais e no padrão de absorção durante o crescimento. Em geral, a absorção de nitrogênio, fósforo e potássio segue a mesma tendência que a taxa de acúmulo de biomassa da cultura. As hortaliças folhosas, como a alface, apresentam lenta absorção de nutrientes durante a primeira metade do ciclo de cultivo, sendo que o índice de absorção de nutrientes acelera-se próximo à co- lheita (Papadopoulos, 1999).

Existem algumas informações a respeito das exigências minerais da alface cultivada para consumo in $\mathrm{na}$ tura. Grangeiro et al. (2006) avaliaram o acúmulo de nutrientes de alface até 27 DAT e verificaram que a cultivar Verônica acumulou $0,33 \mathrm{~g} /$ planta de $\mathrm{K}$; $0,24 \mathrm{~g} /$ planta de $\mathrm{N} ; 0,11 \mathrm{~g} /$ planta de P; $0,10 \mathrm{~g} /$ planta de $\mathrm{Mg}$ e $0,05 \mathrm{~g} /$ planta de $\mathrm{Ca}$, sendo observada maior demanda para $\mathrm{N}, \mathrm{P}, \mathrm{K}$ e $\mathrm{Mg}$ no período entre o $22^{\circ}$ e o $27^{\circ}$ DAT e para o $\mathrm{Ca}$, entre o $17^{\circ}$ e o $22^{\circ}$ dia.

Resultado semelhante foi obtido por Agapito et al. (1997) ao avaliarem o acúmulo de nutrientes por plantas de quatro cultivares de alface. Verificaram que a maior absorção de $\mathrm{N}$ ocorreu na $4^{\mathrm{a}}$ semana após o transplantio para todas as cultivares e a de $\mathrm{P}, \mathrm{Ca}$ e $\mathrm{Mg}$, na $6^{\mathrm{a}}$ semana. A ordem decrescente da extração dos macronutrientes obtida nesse tra- 
balho foi $\mathrm{K}>\mathrm{N}>\mathrm{P}>\mathrm{Ca}>\mathrm{Mg}$. Quanto aos micronutrientes, a ordem decrescente da extração foi $\mathrm{Fe}>\mathrm{Mn}>\mathrm{Zn}>\mathrm{Cu}$, com a máxima absorção ocorrida na $5^{\mathrm{a}}$ semana após o transplantio.

$\mathrm{Na}$ revisão bibliográfica realizada por Ferreira et al. (1993) observa-se que a ordem decrescente da extração dos nutrientes foi $\mathrm{K}>\mathrm{N}>\mathrm{Ca}>\mathrm{P}>\mathrm{Mg}>\mathrm{S}$. Resultados semelhantes foram obtidos por Fernandes et al. (2002), Lopes et al. (2003) e Conversa et al. (2004) no cultivo hidropônico de alface.

Beninni et al. (2005), ao avaliarem a concentração e o acúmulo de macronutrientes em alface cultivar Verônica, verificaram que, no ponto de colheita, a parte aérea das plantas cultivadas no sistema convencional apresentou concentração de: 38,24; 5,74; 78,33; 12,23; 3,11 e 3,87 $\mathrm{g} \mathrm{kg}^{-1}$ e acúmulo de: 372,$78 ; 56,11 ; 765,84 ; 119,05 ; 30,46$ e $37,81 \mathrm{mg} /$ planta, respectivamente, de $\mathrm{N}$, $\mathrm{P}, \mathrm{K}, \mathrm{Ca}, \mathrm{Mg}$ e $\mathrm{S}$.

Embora existam estudos sobre nutrição e recomendações de adubação para o cultivo comercial de alface, raramente se encontram trabalhos que abordem os efeitos dos nutrientes na produção de sementes. Isso se torna importante, pois as quantidades dos nutrientes utilizadas podem ser diferentes daquelas empregadas para a produção comercial, uma vez que a cultura apresenta maior ciclo de desenvolvimento e, certamente, a extração de nutrientes será superior em relação ao cultivo comercial. Segundo Carvalho \& Nakagawa (2000), a exigência nutricional para a maioria das espécies, quando se visa a produção de sementes, torna-se mais intensa, sendo mais crítica por ocasião da formação das sementes, quando considerável quantidade de nutrientes, como o fósforo e o nitrogênio, é para elas translocado.

Com isso, por causa da escassez de informações, o objetivo deste trabalho foi determinar a curva de acúmulo de nutrientes pelas plantas de alface destinadas à produção de sementes.

\section{MATERIAL E MÉTODOS}

Este trabalho foi desenvolvido no município de São Manuel em área pertencente à Universidade Estadual
Paulista, Campus de Botucatu-SP $\left(22^{\circ}\right.$ $46^{\prime} \mathrm{S}, 48^{\circ} 34^{\prime} \mathrm{W}$, altitude de $740 \mathrm{~m}$ ). O experimento foi conduzido em estruturas de proteção, tipo arco, com $20 \mathrm{~m}$ de comprimento, largura de $7 \mathrm{~m}$ e pé-direito de $2,5 \mathrm{~m}$, com altura de $3,8 \mathrm{~m}$ na sua parte mais alta.

O delineamento experimental utilizado foi em blocos ao acaso, com seis tratamentos e cinco repetições. Os tratamentos foram constituídos pelas épocas de coleta das plantas $(0 ; 20 ; 34 ; 49 ; 69$ e 112 dias após o transplante).

Foi utilizado para enchimento dos vasos um Latossolo Vermelho Distrófico Típico (Embrapa, 2006) com os seguintes resultados obtidos na análise química: $\mathrm{pH}\left(\mathrm{CaCl}_{2}\right)=4,0 ; \mathrm{P}_{\text {resina }}=2 \mathrm{mg}$ $\mathrm{dm}^{-3}$; matéria orgânica $=5 \mathrm{~g} \mathrm{dm}^{-3} ; \mathrm{V} \%=$ 16; e os valores de $\mathrm{H}+\mathrm{Al}$; $\mathrm{K}$; $\mathrm{Ca}$; $\mathrm{Mg}$; $\mathrm{SB}$ e CTC, expressos em mmol $\mathrm{dm}^{-3}$, respectivamente de: $28 ; 0,2 ; 4,0 ; 1,0 ; 5,2$ e 33,2. Os resultados da análise física do solo foram: 761, 199 e $40 \mathrm{~g} \mathrm{~kg}^{-1}$ de areia, argila e silte, respectivamente.

A correção do solo e a adubação de plantio foram realizadas com base em análise, seguindo-se a recomendação de adubação e calagem para o estado de São Paulo (Trani \& Raij, 1996). A calagem foi realizada 30 dias antes do transplante das mudas, utilizando-se calcário dolomítico de alta reatividade (PRNT $=90 \%$ ). Após 30 dias de incubação, uma nova análise revelou que a saturação por bases chegou a 71\%.

A adubação de plantio correspondeu ao fornecimento de $0,26 \mathrm{~g} /$ planta de $\mathrm{N}$ na forma de sulfato de amônio, 1,6 g/ planta de $\mathrm{K}_{2} \mathrm{O}$ na forma de cloreto de potássio e $500 \mathrm{~g} /$ planta de Biomix ${ }^{\circledR}$ como fonte de matéria orgânica. A análise química do Biomix ${ }^{\circledR}$ indicou valor de $\mathrm{pH}=7,7$ e de $\mathrm{MO} ; \mathrm{N} ; \mathrm{P}_{2} \mathrm{O}_{5} ; \mathrm{K}_{2} \mathrm{O}$; $\mathrm{Ca}$; $\mathrm{Mg}$ e de $\mathrm{S}$ expressos em \%, respectivamente, de 53; 1,30; 0,90;0,47; 6,80; 0,25 e 0,34 . A relação $\mathrm{C} / \mathrm{N}$ foi de $23 / 1$ e a umidade do Biomix ${ }^{\circledR}$ de $60 \%$. Todo fósforo foi fornecido apenas no plantio na dose de 3,9 g/planta, utilizando-se a fonte superfosfato triplo.

Foram realizadas adubações de cobertura aos 8, 15 e 21 dias após o transplante (DAT). Em cada aplicação, foram fornecidos $0,19 \mathrm{~g} /$ planta de $\mathrm{N}$, na forma de nitrato de cálcio. Após as plantas atingirem o ponto comercial (34 DAT), realizou-se a aplicação semanal de $0,27 \mathrm{~g} /$ planta de $\mathrm{N}$ e de $0,44 \mathrm{~g} /$ planta de $\mathrm{K}_{2} \mathrm{O}$ até a colheita das sementes (112 DAT), fornecendo em cobertura um total de 3,6 g/planta de $\mathrm{N}$ e 4,8 g/planta de $\mathrm{K}_{2} \mathrm{O}$ no ciclo da planta, na forma de nitrato de cálcio e de nitrato de potássio. Aos 36 DAT, foi fornecida a solução Sarruge de micronutrientes contendo: $500 \mu \mathrm{g} \mathrm{L}^{-1}$ de B; $39 \mu \mathrm{g} \mathrm{L}^{-1}$ de $\mathrm{Cu} ; 722$ $\mu \mathrm{g} \mathrm{L}{ }^{-1}$ de Cl; $502 \mu \mathrm{g} \mathrm{L}^{-1}$ de Mn; $12 \mu \mathrm{g}$ $\mathrm{L}^{-1}$ de $\mathrm{Mo}$ e $98 \mu \mathrm{g} \mathrm{L}^{-1}$ de $\mathrm{Zn}$. Diluiu-se $1 \mathrm{~mL}$ dessa solução em $1 \mathrm{~L}$ de $\mathrm{H}_{2} \mathrm{O}$ e foram fornecidos $200 \mathrm{~mL} /$ planta dessa solução diluída.

Utilizou-se a cultivar de alface tipo crespa 'Verônica', e a semeadura foi realizada no dia 25/09/03 em bandejas de poliestireno expandido de 128 células contendo substrato comercial para hortaliças. As mudas foram transplantadas em 30/10/03, para vasos de plástico com altura de $25 \mathrm{~cm}$ e diâmetro de $28 \mathrm{~cm}$, com capacidade de $13 \mathrm{~L}$, sendo conduzida uma planta por vaso, espaçadas em 1,0 m entre linhas e $0,5 \mathrm{~m}$ entre plantas (centro a centro dos vasos).

A colheita das sementes foi parcelada em sete vezes e realizada manualmente na maturidade fisiológica, na fase de "pêlos brancos" ("penugem branca") sobre as inflorescências, conforme Reghin et al. (2000), iniciando-se aos 84 dias após o transplante (DAT) e finalizando-se aos 112 DAT. Assim que coletadas, as sementes foram levadas para a câmara seca a $40 \%$ de umidade relativa e à temperatura de $20^{\circ} \mathrm{C}$, para melhor conservação.

As coletas das plantas para análise química foram realizadas em seis épocas: na fase de muda (dia do transplante = 0 DAT); na época da diagnose foliar para avaliação do estado nutricional da alface (recomendada por Malavolta et al. (1997), 20 DAT); quando as plantas atingiram o ponto comercial para consumo de alface (34 DAT); no início do pendoamento (49 DAT); no início do florescimento (69 DAT), e na última colheita das sementes (112 DAT). Estas datas foram escolhidas por representarem etapas importantes do ciclo.

Assim que coletadas, as amostras (parte aérea e sementes) foram levadas ao laboratório de análise química 
de plantas da UNESP e devidamente lavadas com água deionizada. Após a remoção da água utilizada na lavagem das amostras, elas foram colocadas em saco de papel, identificadas e levadas para secagem em estufa de circulação forçada de ar a $65^{\circ} \mathrm{C}$, até atingirem massa constante conforme Malavolta et al. (1997). A partir dos 49 DAT, as amostras foram deixadas na estufa secando por um período maior que 72 horas, para que estivessem totalmente secas. Posteriormente, com o uso da balança analítica, foi obtida a massa de material seco da amostra de cada planta.

Em seguida, cada amostra passou pela moagem no moinho tipo Willey, sendo acondicionadas em sacos plásticos fechados. A digestão sulfúrica foi utilizada para a obtenção do extrato visando a determinação de nitrogênio total; a digestão nítrico-perclórica foi utilizada para a obtenção dos extratos para as determinações dos teores totais na massa seca dos nutrientes: fósforo, potássio, cálcio, magnésio, enxofre, cobre, ferro, manganês e zinco; e a digestão por via seca foi utilizada para a obtenção do extrato visando a determinação de boro, conforme métodos apresentados por Malavolta et al. (1997).

O nitrogênio foi quantificado pelo método semi-micro Kjeldahl, fósforo e boro por colorimetria, potássio por fotometria de chama e cálcio, magnésio, enxofre, cobre, manganês, zinco e ferro por espectrofotometria de absorção atômica.

A partir das análises químicas, foram determinados os teores de nitrogênio, fósforo, potássio, cálcio, magnésio e enxofre em $\mathrm{g} \mathrm{kg}^{-1}$, e os teores de boro, cobre, ferro, manganês e zinco em $\mathrm{mg}$ $\mathrm{kg}^{-1}$.

$\mathrm{O}$ acúmulo dos nutrientes foi obtido pela multiplicação do teor de cada nutriente pela massa de material seco da amostra, expressando-se os resultados dos macronutrientes em mg/planta e dos micronutrientes em $\mu \mathrm{g} /$ planta.

Todos os resultados foram obtidos a partir de cinco repetições. Eram cinco linhas no sentido longitudinal da estrutura de cultivo protegido, sendo amostrada, ao acaso, uma planta de cada linha em cada época. Os acúmulos de massa de material seco da parte aérea e dos nu- trientes ao longo das épocas avaliadas foram submetidos à análise de variância pelo teste $\mathrm{F}$ através do software Sisvar 4.6 e, quando significativos, foram ajustadas equações não lineares, através do software Microcal Origin 6.0, sendo que, para o acúmulo da massa seca da parte aérea das plantas e de todos os nutrientes, o melhor ajuste foi para a função de Boltzmann, que produz uma curva sigmoidal.

Equação:

$$
y=\frac{A_{1}-A_{2}}{1+e^{\left(x \cdot x_{0}\right) / d x}}+A_{2}
$$

em que $\mathrm{x}=($ dias após o transplante $)$

\section{RESULTADOS E DISCUSSÃO}

A massa seca da parte aérea das plantas (caule + folhas + hastes florais + sementes) ajustou-se a função de Boltzmann (curva sigmoidal) (Tabela 1). Foi crescente ao longo das épocas avaliadas e as plantas apresentaram, ao final do ciclo, massa seca de $73 \mathrm{~g} /$ planta (Figura 2F), valor superior ao obtido por Izzeldin et al. (1980), também visando produção de sementes, que foi de 52,6 $\mathrm{g} / \mathrm{planta}$. Este resultado demonstra não ter havido restrição no crescimento e acúmulo de massa seca pelas plantas por ter sido utilizado vaso.

No ponto comercial (34 DAT), a massa seca da parte aérea das plantas foi de 11,42 g/planta, valor superior ao relatado por Arruda Júnior et al. (2005), que obtiveram, no máximo, 4,35 g/ planta de massa seca, no entanto, foi para a cultivar crespa 'Cacheada'. Para a cultivar Verônica, Grangeiro et al. (2006) e Cézar (2005) obtiveram massa seca de 6,4 e $8,15 \mathrm{~g} /$ planta, respectivamente, também inferiores ao obtido neste trabalho.

É importante observar que após o ponto comercial (34 DAT), a massa seca da parte aérea teve um incremento da ordem de cinco vezes. Isso significa dizer que a planta teve seu maior incremento em massa seca após o ponto comercial e, portanto, a demanda por nutrientes foi muito maior, conforme será discutido posteriormente.

Quanto aos macronutrientes, as quantidades de nitrogênio $(\mathrm{N})$, fósforo $(\mathrm{P})$, potássio $(\mathrm{K})$, cálcio $(\mathrm{Ca})$, magnésio $(\mathrm{Mg})$ e enxofre (S) acumuladas na massa seca da parte aérea das plantas ao longo das épocas avaliadas ajustaram-se à função de Boltzmann (curva sigmoidal) (Tabela 1 e Figura 1).

A curva de acúmulo indicou que a maior demanda por N (Figura 1A) ocorreu do período do desenvolvimento vegetativo ao início do florescimento (20 aos 69 DAT), com média de $19 \mathrm{mg}$ / dia/planta de N. Já para P (Figura 1B), K (Figura 1C), Ca (Figura 1D), Mg (Figura 1E) e $\mathrm{S}$ (Figura 1F), a maior demanda por esses nutrientes ocorreu do período de início do pendoamento ao início do florescimento (49 a 69 DAT), com média de 4,$3 ; 38 ; 18,5 ; 3,4$ e 1,7 mg/dia/planta, respectivamente.

Quanto ao N (Figura 1A), o acúmulo foi crescente até o início do florescimento (69 DAT), tendendo a estabilizar a partir dessa época, de modo semelhante

Tabela 1. Parâmetros da equação não linear ajustada para a massa seca e quantidade de macronutrientes acumulados na parte aérea das plantas (parameters of the non linear equation adjusted to the dry matter and the macronutrients accumulated in the aboveground part of the plants). São Manuel, UNESP, 2003/2004.

\begin{tabular}{crrrcl}
\hline Nutriente & \multicolumn{1}{c}{$\mathbf{A}_{\mathbf{1}}$} & \multicolumn{1}{c}{$\mathbf{A}_{\mathbf{2}}$} & \multicolumn{1}{c}{$\mathbf{x}_{\mathbf{0}}$} & $\mathbf{d x}$ & $\mathbf{R}^{\mathbf{2}}$ \\
\hline $\mathrm{N}$ & $-52,2088$ & 1191,4831 & 46,9302 & 14,2132 & 0,99 \\
$\mathrm{P}$ & 6,6577 & 168,2961 & 57,2837 & 10,9085 & 0,97 \\
$\mathrm{~K}$ & $-89,0638$ & 2343,7685 & 51,7538 & 15,2560 & 0,99 \\
$\mathrm{Ca}$ & $-18,6404$ & 1062,2316 & 60,7611 & 14,8451 & 0,99 \\
$\mathrm{Mg}$ & $-3,7569$ & 191,2563 & 59,9176 & 15,7366 & 0,99 \\
$\mathrm{~S}$ & 0,0681 & 80,6836 & 57,5700 & 13,2680 & 0,99 \\
Massa seca & $-1,0471$ & 73,9342 & 55,1836 & 12,3361 & 0,99 \\
\hline
\end{tabular}

$\mathrm{R}^{2}=$ coeficiente de determinação. 
Tabela 2. Parâmetros da equação não linear ajustada para a quantidade de micronutrientes acumulados na parte aérea das plantas (parameters of the non-linear equation adjusted to the micronutrients accumulated in the aboveground part of the plants). São Manuel, UNESP, $2003 / 2004$.

\begin{tabular}{lrrrrr}
\hline Nutriente & \multicolumn{1}{c}{$\mathbf{A}_{1}$} & \multicolumn{1}{c}{$\mathbf{A}_{2}$} & $\mathbf{x}_{0}$ & $\mathbf{d x}$ & $\mathbf{R}^{2}$ \\
\hline $\mathrm{B}$ & $-25,7318$ & 1054,0101 & 53,2078 & 14,1053 & 0,99 \\
$\mathrm{Cu}$ & $-36,7350$ & 765,2195 & 76,9166 & 23,5905 & 0,99 \\
$\mathrm{Fe}$ & $-281,8558$ & 45499,5220 & 79,5117 & 14,3138 & 0,99 \\
$\mathrm{Mn}$ & $-234,4051$ & 7137,2198 & 75,7901 & 20,9311 & 0,99 \\
$\mathrm{Zn}$ & $-11,2808$ & 2472,9470 & 70,6926 & 14,7821 & 0,99 \\
\hline
\end{tabular}

$\mathrm{R}^{2}=$ coeficiente de determinação.

ao que ocorreu com o acúmulo de massa de material seco das plantas (Figura $2 \mathrm{~F}$ ). A quantidade de $\mathrm{N}$ acumulada ao final do ciclo (112 DAT) foi de $1.174 \mathrm{mg} /$ planta. A alface para produção de sementes encontrava-se com 6,5\%,30\%, $50 \%$ e $84 \%$ do total do $\mathrm{N}$ acumulado (1.174 mg/planta), aos 20, 34, 49 e 69 DAT respectivamente (Figura 1A), ou seja, a alface para produção de sementes acumulou apenas $16 \%$ do total de $\mathrm{N}$ na fase de maturação das sementes (após o início do florescimento), provavelmente em decorrência da senescência das folhas e da redistribuição do $\mathrm{N}$ destas para as partes reprodutivas.

Quanto ao P (Figura 1B), a quantidade acumulada desse nutriente ao final do ciclo (112 DAT) foi de $165 \mathrm{mg} /$ planta. A alface para a produção de sementes necessitou de $6 \%, 25 \%, 28 \%$ e $81 \%$ do total do $\mathrm{P}$ acumulado (165 mg/planta), aos 20, 34, 49 e 69 DAT, respectivamente, ou seja, apenas $19 \%$ na fase de maturação das sementes (após o início do florescimento). Nota-se que, entre os 50 e 70 DAT, ou seja, entre o início do pendoamento e o início do florescimento, foram acumulados cerca de $50 \%$ do $\mathrm{P}$ de que a planta necessitou. Possivelmente, neste estádio, o P seja armazenado para posterior redistribuição para as sementes (principal dreno de reserva). Grant et al. (2001) verificaram que, para trigo, $45 \%$ do $\mathrm{P}$ total da parte aérea tinha sido absorvido até o florescimento e, à medida que a planta se desenvolvia, o $\mathrm{P}$ era removido das folhas e dos caules e direcionado para as sementes.

$\mathrm{O} \mathrm{K}$ foi o nutriente mais acumulado pela planta de alface para produção de sementes. Aos 112 DAT, o acúmulo foi de $2.296 \mathrm{mg} / \mathrm{planta}$. A planta necessitou de $5,7 \%, 24 \%, 43 \%$ e $77 \%$ do total do
$\mathrm{K}$ acumulado (2.296 mg/planta), aos 20, 34, 49 e 69 DAT, respectivamente (Figura 1C). Neste caso, cerca de 23\% após o início do florescimento (69 DAT) até a colheita das sementes.

Quanto ao Ca, aos 112 DAT, o acúmulo foi de $1.028 \mathrm{mg} /$ planta. A planta necessitou de 3\%, 15\%, 29\% e $65 \%$ do total do Ca acumulado, aos 20, 34, 49 e 69 DAT, respectivamente (Figura 1D). Neste caso, 35\% de Ca foram absorvidos após o início do florescimento (69 DAT).

O acúmulo de $\mathrm{Mg}$, aos 112 DAT, foi de $191 \mathrm{mg} /$ planta. A planta necessitou de 3,8\%, $19 \%, 30 \%$ e $67 \%$ do total do $\mathrm{Mg}$ acumulado, aos 20, 34, 49 e 69 DAT, respectivamente (Figura 1E). Assim como para o $\mathrm{Ca}$, cerca de $33 \%$ do $\mathrm{Mg}$ foram absorvidos após o início do florescimento (69 DAT), ou seja, na fase de maturação das sementes.

Quanto ao S, aos 112 DAT, o acúmulo foi de $79 \mathrm{mg} /$ planta. A planta necessitou de $5,5 \%, 17 \%, 24 \%$ e $63 \%$ da média do total do S acumulado, aos 20, 34, 49 e 69 DAT, respectivamente (Figura 1F). Cerca de $37 \%$ do $\mathrm{S}$ foram absorvidos na fase de maturação das sementes.

Para o $\mathrm{Mg}$, assim como para o $\mathrm{K}$, o Ca e o P, a quantidade acumulada na parte aérea das plantas foi crescente até a época da colheita das sementes (112 DAT), o que não ocorreu com o $\mathrm{N}$ e o S; provavelmente isso tenha ocorrido pelo fato de que na semente, o $\mathrm{Mg}, \mathrm{K}, \mathrm{Ca}$ e o P são armazenados nos sais do ácido fítico, constituindo a fitina (Copeland \& McDonald, 1995; Marschner, 1995).

A média da quantidade de macronutrientes acumulados na parte aérea das plantas de alface para a produção de sementes no final do ciclo, em ordem decrescente e em mg/planta, foi:
$2.262>1.133>1.060>188>160>73$, de $\mathrm{K}>\mathrm{N}>\mathrm{Ca}>\mathrm{Mg}>\mathrm{P}>\mathrm{S}$, respectivamente. Esse maior acúmulo de potássio também foi observado para a alface 'Verônica' no ponto comercial, porém, em quantidades menores, nessa mesma cultivar por Beninni et al. (2005) e Grangeiro et al. (2006).

Pelo fato de não ter sido encontrado trabalho sobre curvas de acúmulo de macronutrientes pela planta de alface para a produção de sementes, procurouse comparar esse acúmulo com a alface para o consumo de folhas.

Ferreira et al. (1993) e Beninni et al. (2005) verificaram que a ordem decrescente de acúmulo de macronutrientes para a produção de alface foi: $\mathrm{K}>\mathrm{N}>\mathrm{Ca}>\mathrm{P}>\mathrm{Mg}>\mathrm{S}$, resultado semelhante ao obtido neste trabalho para a produção de sementes, com exceção da inversão do $\mathrm{P}$ e do $\mathrm{Mg}$, que apresentaram valores bem próximos neste trabalho.

Ao comparar o acúmulo de macronutrientes obtidos por Beninni et al. (2005) pela alface cultivar Verônica para o consumo de folhas, pôde-se verificar que a planta para a produção de sementes acumulou quantidade superior de todos os macronutrientes: 2,3 vezes a mais de N; 2,0 de P; 2,5 de K; 7,2 de Ca; 4,6 de $\mathrm{Mg}$ e 1,4 de $\mathrm{S}$, indicando que, quando se busca produção de sementes de alface, a necessidade de macronutrientes é bem maior e, portanto, a adubação deve ser diferente. Deve-se destacar a importância da calagem, pois tanto o $\mathrm{Ca}$ como o $\mathrm{Mg}$ foram os nutrientes com maior aumento no acúmulo em relação à alface para consumo.

Quanto aos micronutrientes, à quantidade de boro, cobre, ferro, manganês e zinco acumulada na parte aérea das plantas (caule + folhas + hastes florais + sementes) ao longo das épocas avaliadas, ajustaram-se à função de Boltzmann (curva sigmoidal) (Tabela 2 e Figura 2). Observa-se que houve aumento no acúmulo desses nutrientes mesmo após o florescimento, até o final do ciclo.

A curva de acúmulo indicou que a maior demanda por B ocorreu do período de início do pendoamento ao início do florescimento (49 aos 69 DAT), com média de $19 \mu \mathrm{g} / \mathrm{dia} /$ planta de B (Figura 2A). Já para o $\mathrm{Cu}$, a maior demanda ocorreu do período de início do flores- 


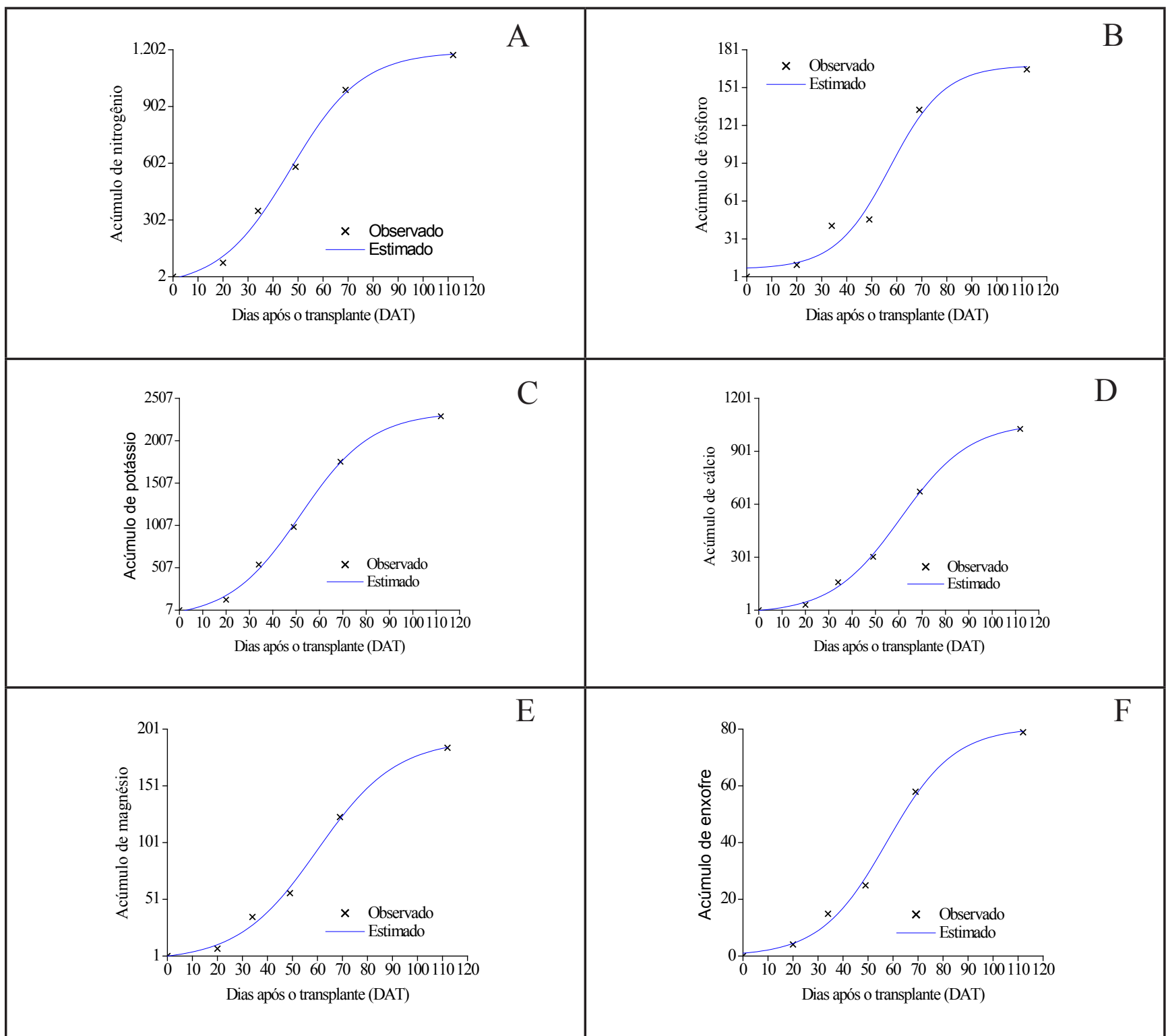

Figura 1. Curva de acúmulo (mg planta $\left.{ }^{-1}\right)$ de nitrogênio (A), fósforo (B), potássio (C), cálcio (D), magnésio (E) e de enxofre (F) pela planta de alface para produção de sementes ao longo do ciclo (accumulation (mg plant ${ }^{-1}$ ) curve of nitrogen (A), phosphorus (B), potassium (C), calcium (D), magnesium (E) and sulphur (F) by lettuce plants for seed production). São Manuel, UNESP, $2003 / 2004$.

cimento até a colheita das sementes (69 aos 112 DAT), com média de $8 \mu \mathrm{g} /$ dia/planta de $\mathrm{Cu}$ (Figura 2B). A maior demanda por Fe $(620 \mu \mathrm{g}$ de ferro/dia/ planta) ocorreu após o início do florescimento, entre os 69 e os 112 DAT (Figura $2 \mathrm{C})$, e para o Mn (74 $\mu \mathrm{g} / \mathrm{dia} /$ planta de $\mathrm{Mn})$, entre o início do pendoamento até a colheita das sementes (49 aos 112 DAT) (Figura 2D). A maior demanda por Zn ocorreu do período de início do pendoamento ao início do florescimento (49 aos 69 DAT), com média de $37 \mu \mathrm{g} /$ dia/planta de Zn (Figura 2E).

A quantidade de B (Figura 2A) acumulada na parte aérea total das plantas aos 112 DAT foi de $1.036 \mu \mathrm{g} /$ planta. A alface para produção de sementes necessitou de $5 \%, 21 \%$, $41 \%$ e $77 \%$ do total do B acumulado aos 20, 34, 49 e 69 DAT, respectivamente. Portanto, cerca de $1 / 4(23 \%)$ do B foi absorvido após o início do florescimento (69 DAT), durante o período de maturação das sementes. Estes resultados comprovam a necessidade deste nutriente estar disponível para a planta de alface, pois o mesmo atua no crescimento do tubo polínico, portanto, isto justifica a maior demanda durante o estádio reprodutivo do que nos estádios de desenvolvimento vegetativo da planta. Há relatos de que, em baixo suprimento de $\mathrm{B}$ à planta, ocorre inibição do florescimento e do desenvolvimento da semente (Marschner, 1995).

Para o $\mathrm{Cu}$ (Figura 2B), a quantidade acumulada na parte aérea total das plantas foi crescente ao longo das épocas avaliadas, sendo, aos 112 DAT, de $618 \mu \mathrm{g} /$ planta. A planta necessitou de $4 \%, 10 \%, 27,5 \%$ e $47 \%$ do total do $\mathrm{Cu}$ acumulado, aos 20, 34, 49 e 69 DAT, respectivamente. Portanto, cerca da metade do cobre (53\%) foi absorvida após o florescimento, ou seja, a grande demanda também foi no estádio reprodutivo da planta. 


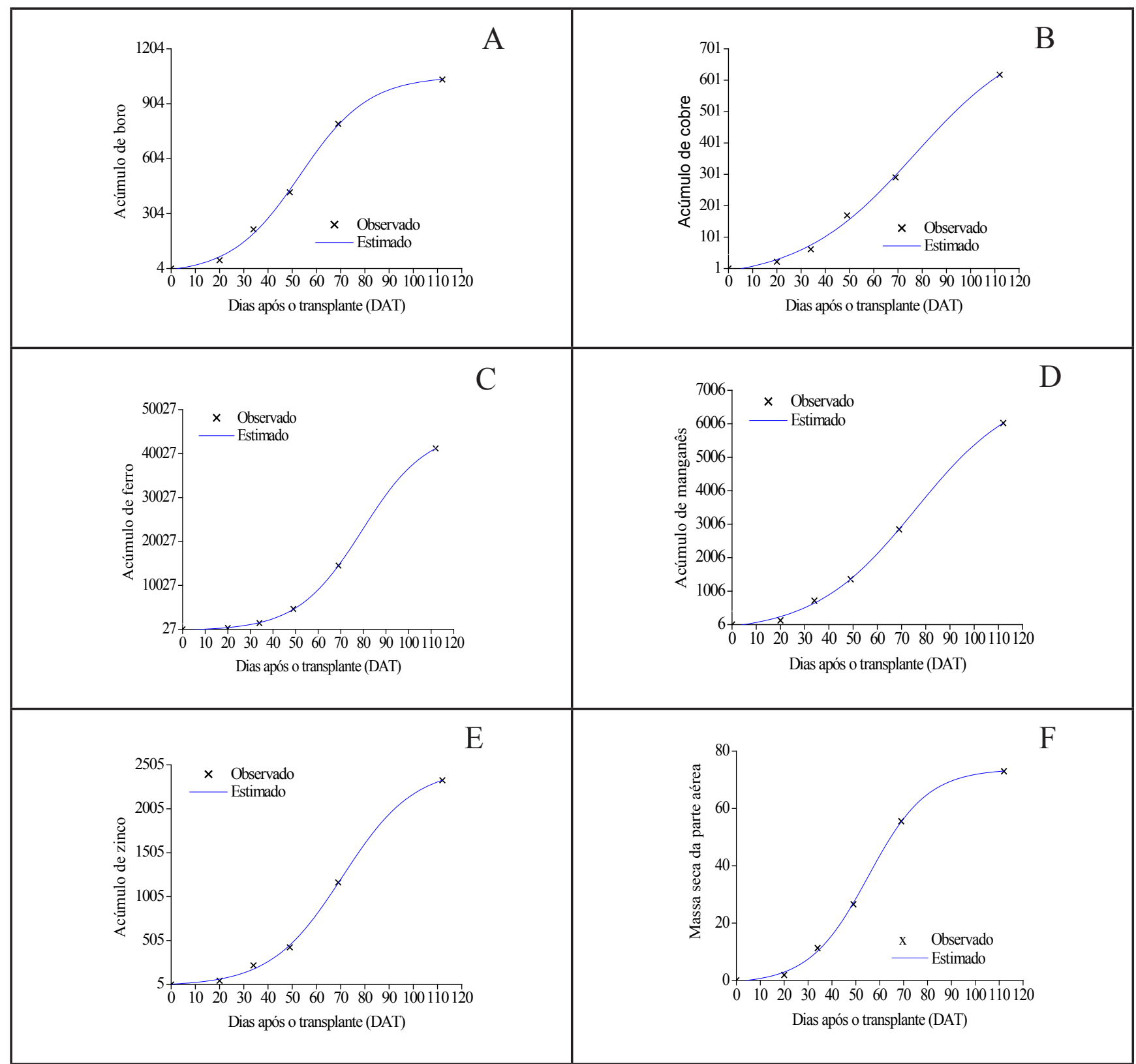

Figura 2. Curva de acúmulo ( $\mu$ g planta- $\left.{ }^{1}\right)$ de boro (A), cobre (B), ferro (C), manganês (D), zinco (E) e de massa seca (F) em $\left(\mathrm{g}\right.$ planta $\left.{ }^{-1}\right)$ pela planta de alface para produção de sementes ao longo do ciclo (accumulation ( $\mu$ g plant ${ }^{-1}$ ) curve of boron (A), copper (B) iron (C), manganese (D), zinc (E) and dry matter (F) (g plant $\left.{ }^{-1}\right)$ by lettuce plants for seed production). São Manuel, UNESP, 2003/2004.

A quantidade de $\mathrm{Fe}$ (Figura 2C) acumulada na parte aérea total das plantas aos 112 DAT foi de $41.213 \mu \mathrm{g} /$ planta. A planta necessitou de $0,6 \%, 3 \%, 12 \%$ e $26 \%$ da média total do Fe acumulado, aos 20, 34, 49 e 69 DAT, respectivamente; portanto, a maior quantidade $(74 \%)$ foi absorvida após o florescimento, ou seja, a grande demanda foi no estádio reprodutivo da planta.

Para o Mn (Figura 2D), a quantidade acumulada na parte aérea total das plantas foi crescente ao longo das épocas avaliadas, sendo, aos 112 DAT, de 6.028 $\mu \mathrm{g} /$ planta. A alface para produção de sementes necessitou de $2 \%, 12 \%, 23 \%$ e $47 \%$ do total do Mn acumulado aos 20 , 34, 49 e 69 DAT, respectivamente. Assim como para o $\mathrm{Cu}$, também para o $\mathrm{Mn}$, cerca da metade (53\%) foi absorvida após o florescimento, ou seja, a grande demanda foi no estádio reprodutivo da planta.

A quantidade acumulada de $\mathrm{Zn}$ na parte aérea total das plantas aos 112 DAT foi de $2.329 \mu \mathrm{g} /$ planta (Figura 2E). A planta necessitou de 2\%, 9,6\%, 18\% e $50 \%$ do total do $\mathrm{Zn}$ acumulado aos 20 ,
34, 49 e 69 DAT, respectivamente. Ametade $(50 \%)$ do $\mathrm{Zn}$ foi absorvida após o florescimento, ou seja, a grande demanda também foi no estádio reprodutivo da planta. Provavelmente essa tendência do Zn deve-se ao alongamento da haste floral no pendoamento, pelo fato de este elemento ser essencial para a síntese do triptofano que, por sua vez, é o precursor do ácido indol acético (AIA), hormônio de crescimento com função também de promover alongamento de segmentos de caules (Malavolta et al., 1997; Taiz \& Zeiger, 2004). 
Lott et al. (1995) descreveram que, frequentemente, a maioria do $\mathrm{K}, \mathrm{Mg}, \mathrm{Ca}$, $\mathrm{Mn}, \mathrm{Fe}$ e $\mathrm{Zn}$ encontrados nas sementes estão associados com o ácido fítico via associações iônicas com a carga negativa dos grupos fosfatos e são utilizados na maturação das sementes. Com a germinação, a fitina é degradada pela ação da fitase, uma fosfatase, e então esses cátions são mobilizados para regiões de crescimento da plântula para serem utilizados no metabolismo. Com isso, pode-se explicar a alta demanda por esses nutrientes, em especial para os micronutrientes a partir do início do florescimento, lembrando que, no caso do $\mathrm{Zn}$, ocorreu maior absorção entre o início do pendoamento até o final do ciclo, explicada, anteriormente, pelo rápido crescimento do caule e pela sua participação na maturação das sementes.

Quanto ao $\mathrm{Cu}$, a maior demanda no estádio reprodutivo deve-se à sua importância na formação da antera, pois em deficiência, segundo Marschner (1995), observou-se um número bem menor de grãos de pólen por antera e, particularmente, a inviabilidade do pólen, além de essa deficiência afetar mais a formação de sementes e frutos do que o crescimento vegetativo.

O B e o $\mathrm{Zn}$ apresentaram cerca de $3 / 4$ do acúmulo após o florescimento, e apenas $25 \%$ do B e $50 \%$ do $\mathrm{Zn}$ antes do florescimento. Quanto ao B, a sua função no crescimento do tubo polínico, é o principal fator responsável pela sua maior demanda durante o estádio reprodutivo do que no desenvolvimento vegetativo da planta. Há relatos de que em baixo suprimento de $\mathrm{B}$ à planta, ocorre inibição do florescimento e do desenvolvimento da semente (Marschner, 1995).

No caso dos micronutrientes, em especial o $\mathrm{Cu}, \mathrm{Fe}, \mathrm{Mn}$ e $\mathrm{Zn}$, mais de $50 \%$ desses nutrientes foram acumulados a partir do florescimento. Isso indica a necessidade de se manejar a adubação de forma a complementar esses micronutrientes num período que antecede este estádio, caso os teores destes micronutrientes estejam baixos nas plantas.

A média da quantidade de micronutrientes acumulada na parte aérea total das plantas de alface para produção de sementes no final do ciclo, em ordem decrescente e em $\mu \mathrm{g} /$ planta, foi: $42.873>5.913>2.319>1.033>640$, de $\mathrm{Fe}>\mathrm{Mn}>\mathrm{Zn}>\mathrm{B}>\mathrm{Cu}$, respectivamente, sendo cerca de 1,6 vez a mais de B; 4,3 vezes de $\mathrm{Cu}$; 10,3 vezes de Fe; 3,4 vezes de $M n$ e 0,9 vez de $Z n$ em relação à alface para consumo de folhas, conforme Ferreira et al. (1993). Constata-se que, quando se busca a produção de sementes de alface, a necessidade de micronutrientes é maior. Essa maior absorção de Fe e Mn, também foi observado por Furlani (1997) no ponto comercial da alface cultivar Verônica e por Agapito et al. (1997) em quatro cultivares de alface.

Conclui-se que o período de maior demanda da maioria dos macronutrientes pela planta de alface para produção de sementes foi entre o início do pendoamento e o início do florescimento. Devese destacar a importância da calagem, pois o $\mathrm{Ca}$ e o $\mathrm{Mg}$ foram os nutrientes com maior diferença no total acumulado em relação à alface para consumo. No caso dos micronutrientes, em especial o $\mathrm{Cu}, \mathrm{Fe}, \mathrm{Mn}$ e $\mathrm{Zn}$, mais de $50 \%$ desses nutrientes foram acumulados a partir do florescimento. Isso indica a necessidade de manejar a adubação de forma a complementar esses micronutrientes num período que antecede este estádio.

\section{AGRADECIMENTOS}

À Capes, pela concessão de bolsa de doutorado à primeira autora.

\section{REFERÊNCIAS}

AGAPITO PJA; CONTRERAS NU; PINZON H; LAVERDE PH. 1997. Nutrient absorption in four lettuce, Lactuca sativa L., source materials. Agronomia Colombiana 14: 2836.

ARRUDA JÚNIOR SJ; MELO EEC; SILVA MO; SOUSA CES; FREIRE MBGS. 2005. Produtividade e teor de $\mathrm{P}$ de plantas de alface em função de diferentes doses de fósforo no solo. In: CONGRESSO BRASILEIRO DE OLERICULTURA, 45. Resumos... Fortaleza: ABH (CD-ROM).

BENINNI ERY; TAKAHASHI HW; NEVES CSVJ. 2005. Concentração e acúmulo de macronutrientes em alface cultivada em sistemas hidropônico e convencional. Semina 26: $273-282$.
CARVALHO NM; NAKAGAWA J. 2000. Sementes: ciência, tecnologia e produção. Jaboticabal: Funep. 588p.

CÉZAR VRS. 2005. Efeito do processo de compostagem sobre a solubilização e a eficiência agronômica de diferentes fontes de fósforo. Botucatu: UNESP-FCA. 66p (Tese doutorado).

CONVERSA G; SANTAMARIAP; GONNELLA M. 2004. Growth, yield, and mineral content of butterhead lettuce (Lactuca sativa var. capitata) grown in NFT. Acta Horticulturae 659: 621-628.

COPELAND LO; McDONALD MB. 1995. Principles of seed science and technology. New York: Chapman \& Hall. 409p.

EMPRESA BRASILEIRA DE PESQUISA AGROPECUÁRIA. 2006. Sistema brasileiro de classificação de solos. Brasília: Embrapa. $306 \mathrm{p}$.

FERNANDES AA; MARTINEZ HEP; PEREIRA PRG; FONSECA MCM. 2002. Produtividade, acúmulo de nitrato e estado nutricional de cultivares de alface, em hidroponia, em função de fontes de nutrientes. Horticultura Brasileira 20: 195-200.

FERREIRA ME; CASTELLANE PD; CRUZ MCP. 1993. Nutrição e adubação de hortaliças. Piracicaba: Potafós. 480p.

FURLANI PR. 1997. Instruções para o cultivo de hortaliças de folhas pela técnica de hidroponiaNFT. Campinas: Instituto Agronômico. 30p. (Boletim técnico, 168).

GRANGEIRO LC; KAMARGO RC; MEDEIROS MA; SALVIANO AM; NEGREIROS MZ; BEZERRA NETO F; OLIVEIRA SL. 2006. Acúmulo de nutrientes por três cultivares de alface cultivadas em condições do semi-árido. Horticultura Brasileira 24: 190-194.

GRANT CA; FLATEN DN; TOMASIEWICZ DJ; SHEPPARD SC. 2001. A importância do fósforo no desenvolvimento da planta. Informações Agronômicas 95: 1-5.

HAAG PH; MINAMI K. 1981. Nutrição mineral de hortaliças. Campinas: Fundação Cargill. $474 \mathrm{p}$.

IZZELDIN H; LIPPERT LF; TAKATORI FH. 1980. An influence of water stress at different growth stages on yield and quality of lettuce seed. Journal of The American Society for Horticultural Science 105: 68-71.

LOPES MC; FREIER M; MATTE JD; GÄRTNER M; FRANZENER G; CASIMIRO ELN; SEVIGNANI A. 2003. Acúmulo de nutrientes por cultivares de alface em cultivo hidropônico no inverno. Horticultura Brasileira 21: 211215.

LOTT JNA; GREENWOOD JS; BATTEN GD. 1995. Mechanisms and regulation of mineral nutrient storage during seed development. In: KIGEL J; GALILI G (eds). Seed development and germination. New York: Marcel Dekker. p. 215-235.

MALAVOLTA E; VITTI GC; OLIVEIRA SA. 1997. Avaliação do estado nutricional das plantas princípios e aplicações. Piracicaba: Potafós. 319p.

MARSCHNER H. 1995. Mineral nutrition of higher plants. London: Academic Press. 889 p. 
PAPADOPOULOS I. 1999. Tendências da fertirrigação. In: FOLEGATTI MV. (coord). Fertirrigação: citrus, flores e hortaliças. Guaíba: Agropecuária. p. 11-155.

PREMUZIC Z; DE-LOS-RIOS A; CLOZZA M; MININO H; VILELLA F; IORIO AF. 1995. Absorción y distribución de macronutrientes en lechuga. Horticultura Argentina 14: 6873.

RAIJ B; CANTARELLA H; QUAGGIO JA; FURLANI AMC. 1996. Recomendações de adubação e calagem para o Estado de São Paulo. Campinas: Instituto Agronômico \&
Fundação IAC. 285p.

REGHIN MY; OTTO RF; ROCHA A. 2000. Indução do florescimento e produção de sementes de alface com diferentes doses de ácido giberélico. Horticultura Brasileira 18: 171-175.

TAIZ L; ZEIGER E. 2004. Fisiologia vegetal. Porto Alegre: Artmed. 719p.

TRANI PE; RAIJ B. 1996. Hortaliças. In: RAIJ B. Recomendações de adubação e calagem para o estado de São Paulo. Campinas: IAC. p. 157-186.

VILLAS BÔAS RL;ANTUNES CL; BOARETTO
AE; SOUSA VF; DUENHAS LH. 2001. Perfil da pesquisa e emprego da fertirrigação no Brasil. In: FOLEGATTI MV. (coord). Fertirrigação: flores, frutas e hortaliças. Guaíba: Agropecuária. p. 71-103.

VITTI GC; BOARETTO AE; PENTEADO SR. 1994. Fertilizantes e fertirrigação. In: SIMPÓSIO BRASILEIRO SOBRE FERTILIZANTES FLUÍDOS, 1. Anais... Piracicaba: Associação Brasileira para a Pesquisa da Potassa e do Fosfato. p. 261280. 